Vadyba
Journal of Management
2020, № $2(36)$
ISSN 1648-7974

\title{
INTEGRATING BIG DATA INTO DECISION-MAKING IN REAL ESTATE INDUSTRY
}

\author{
Beyza Ali ${ }^{1}$, Nikolai Siniak ${ }^{2}$ \\ ${ }^{1}$ University of Information Science and Technology "St. Paul the Apostle", Ohrid. North Macedonia, ${ }^{2}$ Private Institute \\ of Management and Business, Minsk, Belarus
}

\begin{abstract}
With the developments in technology everything we use became smarter which resulted in an outbreak in data generation, which in turn demanded innovations in technology. The new technologies did not only affect the social life but also changed the dynamics in the way businesses are conducted. Compared to before, today people have platforms where they can state their opinions publicly. As positive opinions can increase the reliability of a product, person, brand or etc. negative opinions can decrease the reliability. The increase in the use of such platforms and smart devices resulted in an unprecedented increase in data generation. Hereby a new phenomenon, called Big Data, emerged. In parallel with these developments, business world came to a point where traditional business models and strategies run short to challenge the requirements of clients. At this point it is important to realize that the only way to stay in the game is to accept the new rules and find a way to integrate them to the businesses' internal processes. In this paper the meaning and the importance of the Big Data phenomena is discussed through its effect on value-creation and decision-making. The process of integrating Big Data into an enterprise's core strategies and decision-making processes is investigated with an emphasis on the importance of value-creation from Big Data. As a result of the conducted literature review, success factors for a successful integration process are suggested. One of the industries that has mostly affected from the emergence of Big Data is real estate industry. A case study on the owner occupation rates in Europe was conducted using the annual report for 2019 of European Mortgage Federation (EMF) with the aim to point out to the advantages of using Big Data and analysis over the traditional methods and to emphasize the significance of adopting data analytics technologies.

KEY WORDS: Big Data; decision-making; value-creation; success factors; real estate.
\end{abstract}

\section{Introduction}

The innovations in technology has affected every aspect of life. With every individual owning at least a laptop or a $\mathrm{PC}$, or both, a smart phone, and perhaps other smart devices, the amount of data generated reached an exceptional speed. This continuous data generation resulted in the emergence of a new phenomenon called "Big Data", which received an extensive attention both by people and business world (Ahsaan; Kaur; Naaz 2020), (Chiheb; Boumahdi; Bouarfa 2019). These unprecedented changes in data generation lead to changes and improvements in technology as people didn't know how to handle this new situation. Big Data caused changes in the peoples' everyday life but it caused a revolution in the overall approach of working and the way businesses are conducted (Chiheb; Boumahdi; Bouarfa 2019), (McNeely; Hahm 2014). Data is considered the as the raw material of the $21^{\text {st }}$ century which can produce valuable information if processed correctly. It's potential being tied strongly to the way it is used and managed, Big Data has not just become a key element in the business world but also has changed the basis of competition. On the other hand, if it is done by people who are not good qualified for data analysis it may result in waste of time and resources or, even worse, in some detrimental decisions (Henke; Bughin; Chui; Manyika; Saleh; Wiseman; Sethupathy 2016).

In this regard, this study investigates the processes of integrating Big Data into decision-making process and suggest the most important steps that an enterprise should take in order to gain leverage from investing in Big Data. The question is "why, how and when to integrate Big Data into decision-making process?" This question is intended to be answered by performing a literature review, which resulted in determination of the success factors that play crucial role in successful integration of Big Data into an enterprises way of work. A case study on owner occupation rates in Europe is also performed in order to lay stress on the role of Big Data in the real estate industry.

\section{Big Data}

As its name suggests, Big Data is a big amount of data generated by different kinds of smart devices that are connected to the internet. Although there is no one unique definition of Big Data that is accepted by everybody, Douglas Laney's definition is the one that is accepted by the majority and is used widely. In 2001, Laney introduced the $3 \mathrm{~V}$ 's, namely Volume, Velocity and Variety, and defined Big Data as "a vast amount of data generated very quickly and containing a large amount of content" (Kościelniaka; Putoa; 2015), (Laney 2001), (Patgiri; Ahmed 2016). In short, Big Data is a massive amount of data that can have different structures and properties, which are generated in various formats like data voice, text, images, videos, $\log$ files, transaction data, social media interactions (Poleto; de Carvalho; Costa 2015) and so on, through a wide spectrum of devices. 


\section{Value-Creation and Decision-Making Using Big Data}

Big Data is a dynamically developing area. Business organizations and researchers cooperate to answer their questions about this phenomenon. Their aim is to find a way to become more data-driven by uncovering the cornerstone changes they should perform in order to cope with today's challenges and get advantageous in the business market. The key aspect here is to realize that investing a fortune on technology and having the biggest amount of data is not becoming data-driven. It is rather making the investments wisely and not only to technology but also to people, so that the technology will be used reasonably to make the most out of data such that it will have a strategic value (Wang; Kung; Byrd 2018).

Value-creation, as defined in (Nevo; Wade 2010), is "the ability of firm resources to support strategies intended to fend off threats or capitalize on market opportunities". The point is to create a long-lasting change that will contribute to the success of the organization in every possible way. In (Ghasemaghaei 2019) and (Walls; Barnard 2020) the considerable positive influence of utilizing Big Data analytics on firm valuecreation is emphasized. Becoming a data-driven organization is not something that can happen overnight. Rather it is a long process with no unique list of rules that an organization should obey. As it is suggested by (Walls; Barnard 2020), (Davenport 2014), (Rifkin 2014), a complete structural restructuring is what organizations need to do to end up with success. Even though the process may differ depending on the business area and the objectives of the organizations but the dedication on transformation and restructuring has to continue until the point where everybody will internalize the changes and the system will become "this is how things work in here". When the changes and innovations will sink deep into the culture of the organization it will be easier for the next generation of management and employees to keep the system up to date (Noblet; Simon; Parent 2011). Otherwise, all the effort, commitment and hard work can go down the drain. In this regard it is important to see the bigger picture and realize that it is not Big Data that creates the value, it is the people with the right analytical skills and work in collaboration with people with the necessary domainknowledge. It is important for a firm to be able to create its own learning capabilities and become a selflearning company that can keep pace with the changes will do better than companies that cannot (Huber 1991), (Ghasemaghaei; Calic 2020).
The main objective of creating value from data is to strengthen the company's business strategy which is the core of decision-making process. Decision-making is a cognitive action, which is the final step of a complicated process, where the decision-maker considers every alternative course of action with their possible outcomes and using his/her domain knowledge and experience to decide which action will serve the company's goals the best (Chiheb; Boumahdi; Bouarfa 2019), (Athamena; Houhamdi 2018). Whether it is done by a single person or a team of people with different skill sets, job descriptions and experience levels, the key words for decision-making are the same: understanding, assessment and consideration. The people that are to make decisions make use of the knowledge base of the company which can be taught as the company's organizational memory that was built in the course of time. Every decision-making process, every action plan with its results are stored in this memory (Poleto; de Carvalho; Costa 2015).

The road to having a better functioning company passes through a successful decision-making system. Chiheb et. al in (Chiheb; Boumahdi; Bouarfa 2019) states that "The insights extracted from Big Data have the potential to help organization making smarter and faster decisions that make a real difference in these sectors". Therefore, the organizational restructuring should be centered in strengthening the decisionmaking process. Big companies like Amazon, Google, eBay, UPS and so on are the best examples that show the potential of Big Data. They integrated Big Data and analytics into their core business processes way before people even had an idea of what Big Data is. That is vision. They embraced the new phenomena when it first emerged, mastered the art of using it and now they are reaping the fruits of what they planted (Caesarius; Hohenthal 2018), (Jeble 2018).

The researches that have studied the company's process of integration of Big Data into their businesses show that even though the implementations will differ based on the business area there are some key success factors that play an important role in achieving a successful result. These success factors can be categorized into 6 different categories: people, technology, governance, culture, strategy, and data. The most important factors of each category are identified using the references given in Table 1 and are demonstrated in Fig. 1. For the diagram in Fig. 1 a template designed by Showeet.com is used. 
Table 1. References used to identify the success factors

\begin{tabular}{|c|c|c|c|}
\hline Category & Reference & Category & Reference \\
\hline Governance & $\begin{array}{l}\text { (Wang; Kung; Byrd 2018), } \\
\text { (Vidgen; Shaw; Grant 2017), } \\
\text { (Mazzei; Noble 2017), } \\
\text { (Wamba; Gunasekaran; Akter; Ren; } \\
\text { Dubey; Childe 2017), } \\
\text { (Cato; Gölzer; Demmelhuber 2015), } \\
\text { (Gao; Koronios; Selle 2015), } \\
\text { (Muller; Hart 2016), } \\
\text { (Gupta; George 2016), } \\
\text { (Poleto; de Carvalho; Costa 2017), } \\
\text { (Ghasemaghaei 2019), } \\
\text { (Kotter 1995), } \\
\text { (Brooks; El Gayar; Sarnikar 2015), } \\
\text { (McAfee; Brynjolfsson; Davenport; Patil; } \\
\text { Barton 2012), } \\
\text { (Henke; Bughin; Chui; Manyika; Saleh; } \\
\text { Wiseman; Sethupathy 2016), } \\
\text { (Kabir; Carayannis 2013) }\end{array}$ & Data & $\begin{array}{l}\text { (Henke; Bughin; Chui; Manyika; Saleh; } \\
\text { Wiseman; Sethupathy 2016), } \\
\text { (Poleto; de Carvalho; Costa 2017), } \\
\text { (Vidgen; Shaw; Grant 2017), } \\
\text { (Brooks; El Gayar; Sarnikar 2015), } \\
\text { (Cato; Gölzer; Demmelhuber 2015), } \\
\text { (Gao; Koronios; Selle 2015), } \\
\text { (Muller; Hart 2016), } \\
\text { (Ahangama; Poo 2015) }\end{array}$ \\
\hline People & $\begin{array}{l}\text { (Henke; Bughin; Chui; Manyika; Saleh; } \\
\text { Wiseman; Sethupathy 2016), } \\
\text { (Ghasemaghaei 2019), } \\
\text { (Wang; Kung; Byrd 2018), } \\
\text { (Vidgen; Shaw; Grant 2017), } \\
\text { (Kiron; Prentice; Ferguson 2014), } \\
\text { (Wamba; Gunasekaran; Akter; Ren; } \\
\text { Dubey; Childe 2017), } \\
\text { (Brooks; El Gayar; Sarnikar 2015), } \\
\text { (Cato; Gölzer; Demmelhuber 2015), } \\
\text { (Gao; Koronios; Selle 2015), } \\
\text { (Muller; Hart 2016), } \\
\text { (Mazzei; Noble 2017), } \\
\text { (Kotter 1995), } \\
\text { (Ahangama; Poo 2015) }\end{array}$ & Culture & $\begin{array}{l}\text { (Vidgen; Shaw; Grant 2017), } \\
\text { (Kotter 1995), } \\
\text { (Kabir; Carayannis 2013), } \\
\text { (Kiron; Prentice; Ferguson 2014), } \\
\text { (Brooks; El Gayar; Sarnikar 2015), } \\
\text { (Cato; Gölzer; Demmelhuber 2015), } \\
\text { (Muller; Hart 2016), } \\
\text { (Gupta; George 2016), } \\
\text { (Poleto; de Carvalho; Costa 2017), } \\
\text { (Ghasemaghaei 2019), } \\
\text { (Wang; Kung; Byrd 2018), } \\
\text { (McAfee; Brynjolfsson; Davenport; Patil; } \\
\text { Barton 2012) }\end{array}$ \\
\hline Technology & $\begin{array}{l}\text { (Ghasemaghaei 2019), } \\
\text { (Mazzei; Noble 2017), } \\
\text { (Brooks; El Gayar; Sarnikar 2015), } \\
\text { (Cato; Gölzer; Demmelhuber 2015), } \\
\text { (Gao; Koronios; Selle 2015), } \\
\text { (McAfee; Brynjolfsson; Davenport; Patil; } \\
\text { Barton 2012), } \\
\text { (Gupta; George 2016) }\end{array}$ & Strategy & $\begin{array}{l}\text { (Sheng; Amoah; Wang 2017), } \\
\text { (Poleto; de Carvalho; Costa 2017), } \\
\text { (Vidgen; Shaw; Grant 2017), } \\
\text { (LaValle; Lesser; Shockley; Hopkins; Kru- } \\
\text { schwitz 2011), } \\
\text { (Davenport; Dyché 2013), } \\
\text { (George; Haas; Pentland 2014), } \\
\text { (Brooks; El Gayar; Sarnikar 2015), } \\
\text { (Cato; Gölzer; Demmelhuber 2015), } \\
\text { (Wang; Kung; Byrd 2018), } \\
\text { (Kotter 1995), } \\
\text { (Mazzei; Noble 2017), } \\
\text { (Gao; Koronios; Selle 2015) }\end{array}$ \\
\hline
\end{tabular}




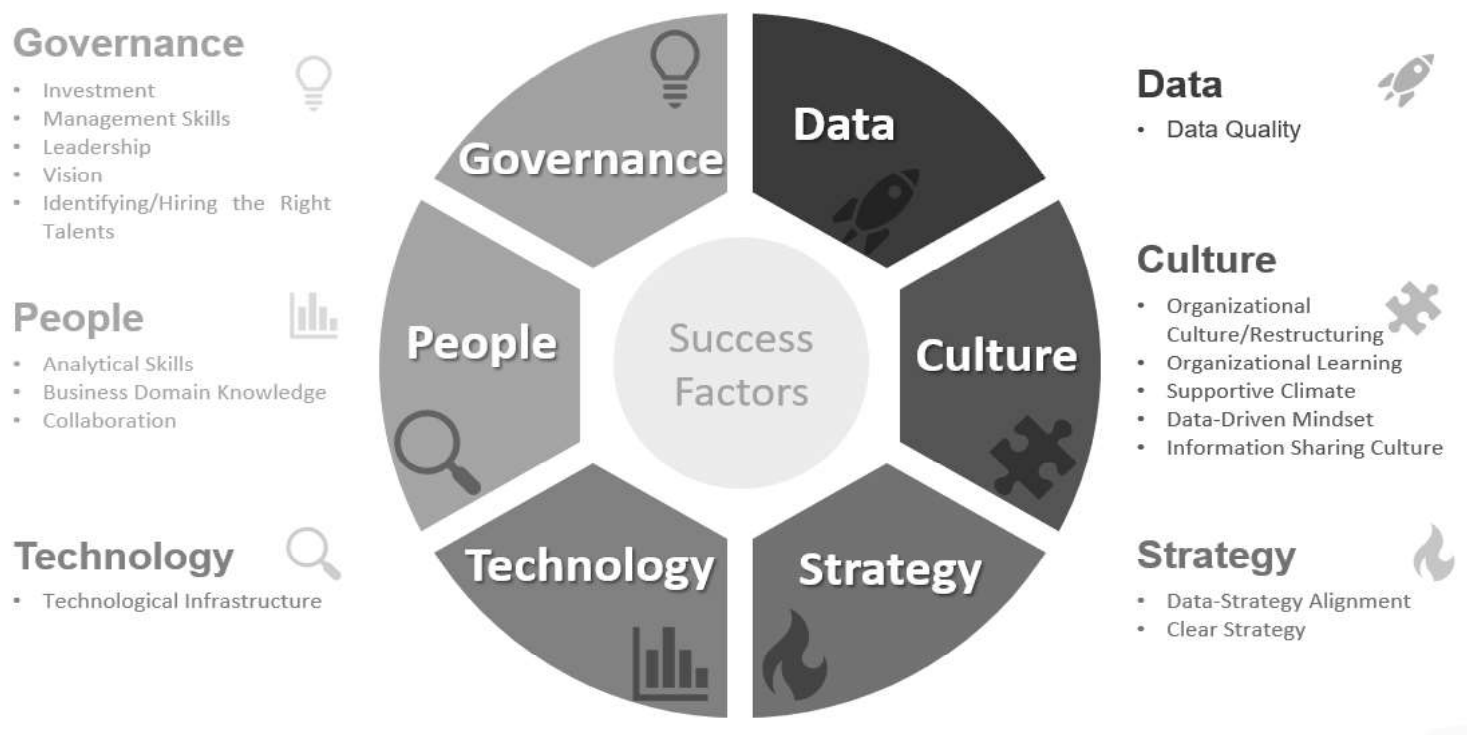

Fig. 1. Success factors.

It is important to understand that these success factors have an effect if they are taken into account together, as it consists of people, tools they will use, qualifications they should acquire and the processes they should conduct. One without another can only give temporary results.

\section{Case Study on Owner Occupation Rates in Eu- rope}

In this case study the annual report for 2019 on mortgage markets and housing developments in Europe and beyond, published by the European Mortgage Federation

(EMF)

(https://hypo.org/ecbc/publications/hypostat/), is analyzed with an aim to uncover the similarities in the European countries with respect to owner occupation rates. A small-scale exploratory analysis was conducted using RStudio.

When analyzing a big dataset which has many observations, it is difficult to find the relationship patterns and make prediction models. Fortunately, there are methods that help the analysts reduce the dimensions and create a simpler dataset that conserve the original patterns and relationships, and moreover finds the unobserved quantities which affects the variables. Factor analysis is the most used technique that seeks to uncover the underlying factors that create the variables by analyzing which factor contributes to the performance of which variable. In other words, factor analysis aims at finding factors that creates the closest estimate correlation matrix to the original correlation matrix created by the original variables. The mathematical representation of this technique is as follows:

$$
\widehat{\Sigma}=\widehat{L} \widehat{L^{T}}+\widehat{\Psi}
$$

where L is called the "loading matrix" composed of the loadings where the loadings are the correlations of the factors to the variables, $L^{T}$ is the transpose of the loading matrix and $\Psi$ is called the uniqueness. Finally, $\Sigma$ is the original matrix (Johnson; Wichern 2007). These values are estimates and that is the reason they have little hats on them. When the estimate loading matrix is multiplied by its transpose and summed with the estimate uniqueness, it gives the estimate of the original matrix.

The factors that are uncovered from the factor analysis are then used for creating linear regression models where the independent variables are the factors instead of the original variables. Linear regression is simply a method trying to make predictions about the values of a dependent variable with respect to one or more independent variables. In other words, it assesses the effects of the independent variables on the dependent variable. The mathematical representation of linear regression is

$Y=\beta_{0}+\beta_{1} z_{1}+\beta_{2} z_{2}+\cdots+\beta_{r} z_{r}+\varepsilon$

where $\mathrm{Y}$ is the dependent variable, $z_{1}, \ldots, z_{r}$ are the independent variables, $\beta_{0}, \ldots, \beta_{r}$ are the coefficients, and $\varepsilon$ is the error term (Johnson; Wichern 2007).

In this study data on housing market in Europe is analyzed with the aim of discovering the relationship of owner occupation rates to different factors. For each variable in the dataset there is a separate spreadsheet provided in (Johnson; Wichern 2007). In each spreadsheet data about different countries for that particular variable is given for years $2000-2017$. Because of the facts that each spreadsheet does not contain information about each country and there are missing values for some years, the data about countries that are present in most of the spreadsheets were collected into a single spreadsheet. For each variable the average values for each country were calculated from the respective spreadsheet. The spreadsheets with less data were excluded from the analysis, resulting in a smaller dataset. Although the dataset is not very big it still needs dimension reduction in order to have more understandable and explicable information. 
Before starting the analysis Kaiser-Meyer-Olkin test (KMO) and Bartlett's sphericity test were performed on the dataset. KMO test is applied to the variable to decide if the dataset is adequate for the factor analysis. It provides an overall value for the dataset and separate values for each variable. An overall $\mathrm{KMO}$ value that is less than 0.6 is considered as insufficient and inadequate for factor analysis. Therefore, variables with KMO values less than 0.6 should be excluded until the overall value exceeds 0.6. Bartlett's test tests if the correlations between variables are greater than would be expected by chance, therefore resulting in a matrix similar to the identity matrix. The datasets which has a significant p-value in the Bartlett's test, that is a value less than 0.05 , are considered as appropriate for further analysis (Rodrigues 2016).

The dataset had a KMO value of 0.581696 . Since the dataset is relatively small only the variables with $\mathrm{KMO}$ values less than 0.5 were excluded. This increased the KMO value to 0.765826 , which is an acceptable value. Bartlett's test gave a p-value less than $2.2 \mathrm{e}-16$, which is much lower than 0.05 . These values tell that the dataset is adequate for factor analysis.

The analysis started with studying the correlations between variables. The correlations are given in Fig. 2 with the meanings of the variables given in Fig. 3 .

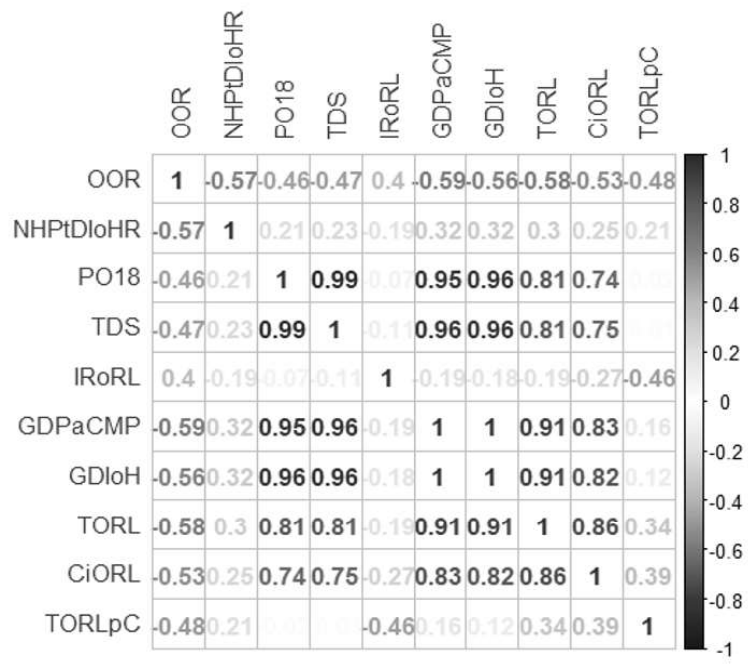

Fig. 2. Correlation matrix of variables.

OOR - Owner Occupation Rates

NHPtDIoHR - Nominal House Price to Disposable Income of Household Ratio

PO18 - Population Over 18 Years

TDS - Total Dwelling Stock

IRoRL - Interest Rates on Residential Loans

GDPaCMP - GDP at Current Market Prices

GDIoH - Gross Disposable Income of Households

TORL - Total Outstanding Residential Loans

CiORL - Change in Outstanding Residential Loans

TORLpC - Total Outstanding Residential Loans per Capita

Fig. 3. Variables with their meanings.

The figure demonstrates that there are very high correlations between the independent variables. For example, PO18 (Population Over 18) has a correlation of 0.99 with TDS (Total Dwelling Stock), and TDS has a correlation of 0.96 with GDPaCMP (GDP at Current Market Prices). These values are showing that there is multicollinearity in

the dataset. The "Variance Inflation Factor" or VIF function in $\mathrm{R}$ calculates the variation inflation factors of all predictors in regression models (https://www.rdocumentation.org/packages/regclass/ve rsions/1.6/topics/VIF). It is commonly accepted that a VIF value greater than 5 or 10 is accepted as large and indicates multicollinearity. Fig. 4. demonstrates the VIF values for the variables when linear regression is performed on the dataset.

$\begin{array}{rrr}\text { NHPTDIOHR } & \text { PO18 } & \text { TDS } \\ 1.310300 & 103.212984 & 153.277799 \\ \text { IRORL } & \text { GDPaCMP } & \text { GDIOH } \\ 1.514808 & 640.110984 & 521.839187 \\ \text { TORL } & \text { CiORL } & \text { TORLPC } \\ 13.943953 & 4.699734 & 3.481572\end{array}$

Fig. 4. VIF values for model0.

It is clear that the dataset needs some dimension reduction and simplification. Firstly, principal component analysis is performed on the dataset in order to decide with how many factors the factor analysis should be performed. Fig. 5 shows the principal components and their effects on the variables.

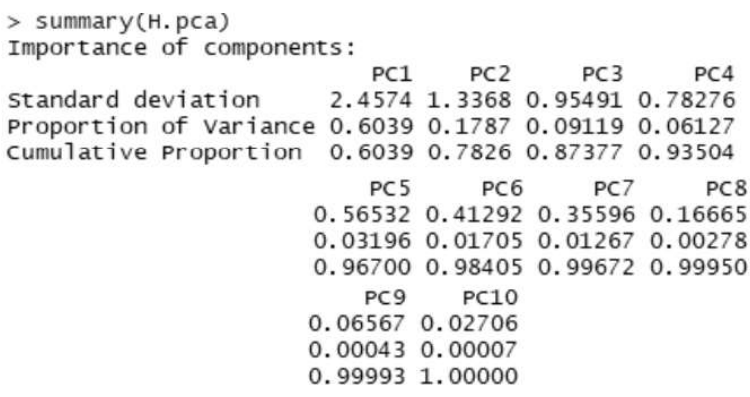

Fig. 5. Principal components.

The proportion of variance tells that the $\mathrm{PC} 1$ explains the $60 \%$ of the variability in the original data, PC2 explains the $17 \%$ of the variability, and PC3 explains the $9 \%$ of the variability. We ignore the other components since they are of less importance. The first three components explain the $86 \%$ of the variability in the dataset. The scree plot given in Fig. 6 also supports the importance of the first three components. We can see that after component 3 , and maybe 4 , there is less change in the variance. As a result, 3 or 4 factors are sufficient for the factor analysis. 


\section{Scree Plot}

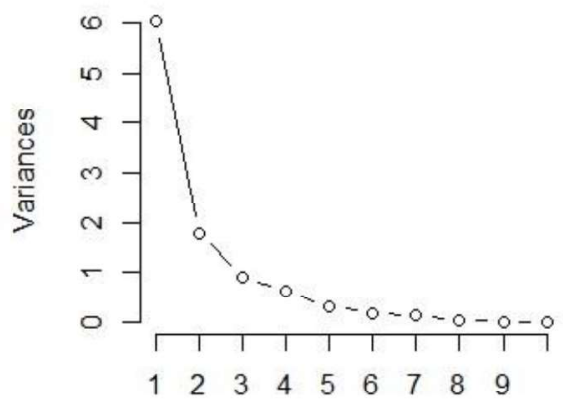

Fig. 6. The effects of number of factors on the variances in the dataset.

Fig. 7 and Fig. 8 give the summary of the factor analysis performed by 3 and 4 factors respectively. The $\mathrm{p}$ values are almost same. The loadings give the correlation between the factors and the variables. The higher the correlation the more effect the factor has on the variable. Discovering the meanings of the factors is out of the scope of this paper and requires more data and information on the dataset.

cal1:

factanal $(x=$ H.data. num2, factors $=3$, scores $=$ "regression" uniquenesses:

\begin{tabular}{|c|c|c|c|c|c|}
\hline OOR & NHPtDIO & & P018 & TDS & IRORL \\
\hline 0.488 & 0.7 & & 0.008 & 0.005 & 0.767 \\
\hline GDP aCMP & GDI & & TORL & CIORL & TORLPC \\
\hline 0.005 & 0.0 & & 0.105 & 0.239 & 0.005 \\
\hline & Factor 1 & Factor & 2 Facto & & \\
\hline$O R$ & -0.431 & -0.477 & -0.31 & & \\
\hline HPtDIOHR & 0.187 & 0.194 & 0.36 & & \\
\hline 018 & 0.992 & & & & \\
\hline DS & 0.992 & & 0.10 & & \\
\hline RORL & & -0.457 & -0.13 & & \\
\hline DP ACMP & 0.929 & 0.170 & 0.32 & & \\
\hline DIOH & 0.933 & 0.128 & 0.33 & & \\
\hline ORL & 0.770 & 0.338 & 0.43 & & \\
\hline IORL & 0.718 & 0.399 & 0.29 & & \\
\hline ORLPC & & 0.994 & & & \\
\hline & & actor $1 \mathrm{~F}$ & Factor 2 & Factor 3 & \\
\hline is loading & & 5.037 & 1.782 & 0.761 & \\
\hline roportior & var & 0.504 & 0.178 & 0.076 & \\
\hline Cumulative & e var & 0.504 & 0.682 & 0.758 & \\
\hline
\end{tabular}

Test of the hypothesis that 3 factors are sufficient. The chi square statistic is 39.63 on 18 degrees of freedom. The p-value is 0.00234

Fig. 7. Summary of factor analysis with 3 factors.

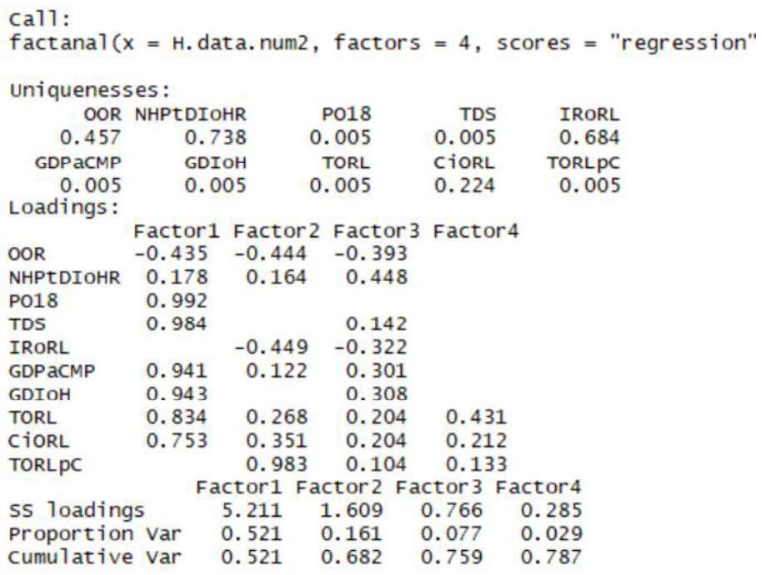

Test of the hypothesis that 4 factors are sufficient. The chi square statistic is 28.65 on 11 degrees of freedom. The $\mathrm{p}$-value is 0.00257
Fig. 8. Summary of factor analysis with 4 factors.

The VIF values, given in Fig. 9 and Fig. 10, for model 1 and model 2 respectively show that factor analysis has dealt with the multicollinearity successfully.

Factor1 Factor2 Factor 3

1.0004691 .0001261 .000587

Fig. 9. VIF values for model1.

\section{Factor1 Factor 2 Factor 3 Factor 4} 1.0007181 .0002021 .0013091 .000476

Fig. 10. VIF values for model2.

Now that we have factors that represent the original variables, we perform linear regression with Owner Occupation Rate as dependent and the factors as independent variables. Table 2 gives us the performances of all three linear regression models.

\begin{tabular}{|c|c|c|}
\hline Models & $\begin{array}{c}\text { Multiple R- } \\
\text { squared }\end{array}$ & $\begin{array}{c}\text { Adjusted R- } \\
\text { squared }\end{array}$ \\
\hline model0 & 0.685 & 0.5275 \\
\hline model1 & 0.5162 & 0.4557 \\
\hline model2 & 0.5535 & 0.4759 \\
\hline
\end{tabular}

Table 2. Linear regression model performances

Although model0 has the highest Multiple Rsquared value it is not the best model because there was multicollinearity in the data used. Taking into account the information VIF values give we can conclude that model 2 is the best model among these three models.

Using the principal components, we can also perform clustering. The factor map given in Fig. 11 demonstrates the suggested three clusters for the countries. Each color represents a different cluster where each cluster contains members that are more similar to each other, and dissimilar to other cluster members.

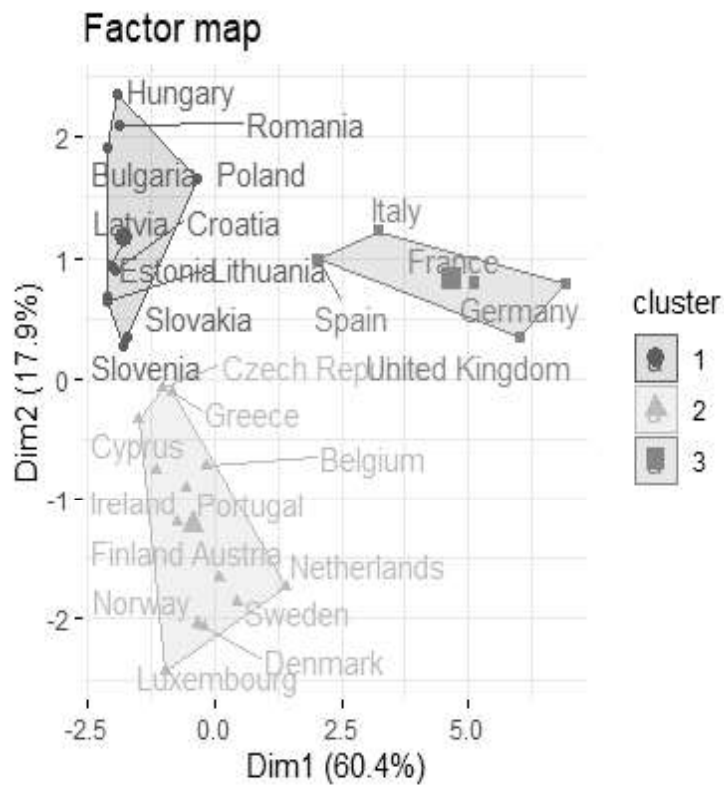

Fig. 11. Factor map. 
Home ownership is an international phenomenon. There are many factors from economical to legal, from social to political, to cultural that affects the home ownership rates in a country. On the other side, housing is an important component of investment and in many countries, it is an important component of wealth (Zhu 2014). Therefore, it has an important impact on the economy. (Cesa-Bianchi 2013) suggest that policymaker should closely monitor the housing cycles and consider the global nature of housing cycles, as shocks to the housing market have deep economic impacts on the country's economy. The analysis provided in this paper does not have a comprehensive explanatory power of homeownership in Europe. Though can be considered the first step for a deeper analysis. This is the point where Big Data comes into play. For a deeper analysis, more detailed data is needed. Uncovering the factors that give us the clusters would provide a better understanding on the real estate markets of the mentioned countries.

\section{Conclusion}

The technological developments came with their challenges. Both technology and internet became an essential part of our daily lives and changed the habits and the routines of the society. Therefore, it raised a need for changes in the way businesses are conducted. At this point, it was, and still is very important for the companies to adapt to the changes if they want to have a place in the business market.

The unprecedented increase in data generation changed the dynamics of the business industries and made it crucial to integrate the ideas and feedbacks of customers or clients, who are the source of the data. As a result of the literature review conducted in this paper, it is concluded that the most important point is to realize that the integration of Big Data into the company's decision-making process is not a one-time operation, it is a process. It requires time, dedication, and continuous effort. The companies should change their mindsets and make using Big Data and analytics a part of the company's culture. Strong collaboration between the employees is very important. Only if all these aspects of transformation come together a company can learn to create value from data and use it to the full potential. The success factors that play a crucial role in a successful integration process are classified into 6 categories, namely, governance, people, technology, data, culture, and strategy.

One of the industries that was affected by these technological developments the most was the real estate industry. The statistical analysis on owner occupation rates in Europe verifies that Big Data and the related analysis technologies surpass the traditional methods. As a result of the principal component analysis, performed using the $\mathrm{R}$ programming language, suggested that there are 3 or 4 latent factors in the Hypostat dataset. Factor analysis is used to the reduce dimensions of the dataset and uncover the factors that define the correlations among the variables. From the results of the factor analysis, it can be seen that 3 factors are able to explain the $86 \%$ of the variability in the dataset, and 4 factors are able to explain the $92 \%$ of the variability. With the help of the principal component analysis it is concluded that 3 is the appropriate cluster number. The clusters are given in Fig. 11, each cluster demonstrated with a different color. For example, Italy, France, Germany, Spain, United Kingdom fall into the same cluster, indicating that these countries have similar owner occupation rates. Now this could be due to different reasons. Finding out what those reasons are is possible by deciphering the meaning of the latent factors. In order to do that we need more data related to the regulations and policies on real estate market of each country, data related to the economy of each country, data about the banking sector, and data about other factors that cause fluctuations in the economy.

\section{References}

Ahangama, S. and Poo, D.C.C. (2015). Improving Health Analytic Process through Project, Communication and Knowledge Management. Proc. of the International Conference on Information Systems, vol. 1, pp. 418 - 427.

Ahsaan, S.U., Kaur, H., and Naaz, S. (2020). An Empirical Study of Big Data: Opportunities, Challenges and Technologies. In S. Patnaik, A.W.H. Ip, M. Tavana, and V. Jain (Eds.), New Paradigm in Decision Science and Management, vol. 1030, pp. 49-65. Springer Singapore, Singapore.

Athamena, B. and Houhamdi, Z. (2018). Model for DecisionMaking Process with Big Data. Journal of Theoretical and Applied Information Technology, vol. 96, issue 17, pp. 5951-5961.

Brooks, P., El Gayar, O. and Sarnikar, S. (2015). A framework for developing a domain specific business intelligence maturity model: Application to healthcare. International Journal of Information Management, vol. 35, pp. $337-345$

Caesarius, L.M. and Hohenthal, J. (2018). Searching for big data: How incumbents explore a possible adoption of big data technologies. Scandinavian Journal of Management, vol. 34, issue 2, pp. 129-140.

Cato, P., Gölzer, P. and Demmelhuber, W. (2015). An Investigation into the Implementation Factors Affecting the Success of Big Data Systems. Proc. of the 11th International Conference on Innovations in Information Technology, pp. 134-139.

Cesa-Bianchi, A. (2013). Housing cycles and macroeconomic fluctuations: A global perspective. Journal of International Money and Finance, vol. 37, pp. 215-238.

Chiheb, F., Boumahdi, F., Bouarfa, H. (2019). A New Model for Integrating Big Data into Phases of Decision-Making Process. Procedia Computer Science, vol. 151, pp. 636642.

Davenport, T.H. (2014). Big Data at Work: Dispelling the Myths, Uncovering the Opportunities. HBS Press, Boston, MA.

Davenport, T.H. and Dyché, J. (2013). Big data in big companies. International Institute for Analytics. [revised 2020 05 25], https://www.sas.com/en_za/whitepapers/bigdatabigcompanies-106461.html.

Gao, J., Koronios, A. and Selle, S. (2015). Towards A Process View on Critical Success Factors in Big Data Analytics Projects. Proc. of the Americas Conference on Information Systems, vol. 1, pp. 824-837.

George, G., Haas, M.R. and Pentland, A. (2014) Big data and management. Academy of Management Journal, vol. 57, issue 2, pp. 321-326. 
Ghasemaghaei, M. (2019). Are firms ready to use big data analytics to create value? The role of structural and psychological readiness. Enterprise Information Systems, vol. 13, issue 5, pp. 650-674.

Ghasemaghaei, M. and Calic, G. (2020). Assessing the impact of big data on firm innovation performance: Big data is not always better data. Journal of Business Research, vol. 108 , pp. 147-162.

Gupta, M. and George, J.F. (2016). Toward the development of a big data analytics capability. Information \& Management, vol. 53, issue 8, pp. 1049-1064.

Henke, N., Bughin, J., Chui, M., Manyika, J., Saleh, T., Wiseman, B. and Sethupathy, G. (2016). The Age of Analytics: Competing in a Data-Driven World. [revised 202002 02], https://www.mckinsey.com/businessfunctions/mckinsey-analytics/our-insights/the-age-ofanalytics-competing-in-a-data-driven-world.

Huber, G.P. (1991). Organizational learning: The contributing processes and the literatures. Organization Science, vol. 2 , issue 1 , pp. 88-115.

Jeble, S. (2018). Role of Big Data in Decision Making. $O p$ erations and Supply Chain Management, vol. 11, issue 1, pp. 36-44.

Johnson, R.A. and Wichern, D.W. (2007). Applied Multivariate Statistical Analysis. Pearson Prentice Hall, New Jersey, USA.

Kabir, N. and Carayannis, E. (2013). Big data, tacit knowledge and organizational competitiveness. Journal of Intelligence Studies in Business, vol. 3, pp. 54-62.

Kiron, D., Prentice, P.K. and Ferguson, R.B. (2014). The analytics mandate. MIT Sloan Management Review, vol. 55, issue 4, pp. 1-21.

Kościelniaka, H. and Putoa, A. (2015). Big Data in decision making processes of enterprises. Procedia Computer Science, vol. 65, pp. 1052-1058.

Kotter, J.P. (1995). Leading Change: Why Transformation $\begin{array}{lllll}\text { Efforts Fail. [revised } & 2020 & 02 & 21]\end{array}$ https://hbr.org/1995/05/leading-change-whytransformation-efforts-fail-2.

Laney, D. (2001). 3D Data Management: Controlling Data Volume, Velocity, and Variety. [revised 202003 05], https://blogs.gartner.com/douglaney/files/2012/01/ad949-3D-Data-ManagementControlling-Data-Volume-Velocity-and-Variety.pdf.

LaValle, S., Lesser, E., Shockley, R., Hopkins, M.S. and Kruschwitz, N. (2011). Big data, analytics and the path from insights to value. MIT Sloan Management Review, vol. 52 , issue 2, pp. 21-31.

Mazzei, M.J. and Noble, D. (2017). Big data dreams: A framework for corporate strategy. Business Horizons, vol. 60 , issue 3, pp. 405-414.

McAfee, A., Brynjolfsson, E., Davenport, T.H., Patil, D.J. and Barton, D. (2012). Big data: the management revolution. Harvard Business Review, vol. 90, issue 10, pp. 60-68. Available: https://hbr.org/2012/10/big-data-the-managementrevolution.

McNeely, C.L. and Hahm, J. (2014). The Big (Data) Bang: Policy, Prospects, and Challenges. Review of Policy Research, vol. 31, issue 4, pp. 304-310.
Muller, L. and Hart, M. (2016). Updating Business Intelligence and Analytics Maturity Models for New Developments, pp. 137-151. In Decision Support Systems VI Addressing Sustainability and Societal Challenges. Springer, Plymouth, UK.

Nevo, S. and Wade, M.R. (2010). The Formation and Value of IT-Enabled Resources: Antecedents and Consequences of Synergistic Relationships. MIS Quarterly, vol. 34, issue 1, pp. 163-183.

Noblet, J.P., Simon, E. and Parent, R. (2011). Absorptive capacity: a proposed operationalization. Knowledge Management Research \& Practice, vol. 9, issue 4, pp. 367-377.

Patgiri, R. and Ahmed, A. (2016). Big Data: The V's of the Game Changer Paradigm. 2016 IEEE 18th International Conference on High Performance Computing and Communications; IEEE 14th International Conference on Smart City; IEEE 2nd International Conference on Data Science and Systems (HPCC/SmartCity/DSS), pp. 17-24.

Poleto, T., de Carvalho, V.D.H., and Costa, A.P.C.S. (2015). The Roles of Big Data in the Decision-Support Process: An Empirical Investigation. In B. Delibašić (Ed.), Decision Support Systems V - Big Data Analytics for Decision Making. ICDSST 2015. Lecture Notes in Business Information Processing, vol. 216, pp. 1021. Springer, Switzerland.

Poleto, T., de Carvalho, V.D.H., and Costa, A.P.C.S. (2017). The Full Knowledge of Big Data in the Integration of Inter-Organizational Information: An Approach Focused on Decision Making. International Journal of Decision Support System Technology, vol. 9, issue 1, pp. 16-31.

Rifkin, J. (2014). The Zero Marginal Cost Society: the Internet of Things, the Collaborative Commons, and the Eclipse of Capitalism. Palgrave Macmillan, New York.

Rodrigues, J. (2016). Factor Analysis. [revised 202005 06], https://rpubs.com/jaelison/135029.

Sheng, J., Amoah, J.A. and Wang, X. (2017). A multidisciplinary perspective of big data in management research. International Journal of Production Economics, vol. 191, pp. 97-112.

Vidgen, R., Shaw, S. and Grant, D.B. (2017). Management challenges in creating value from business analytics. European Journal of Operational Research, vol. 261, issue 2, pp. 626-639.

Walls, C. and Barnard, B. (2020). Success factors of big data to achieve organisational performance. Expert Journal of Business and Management, vol. 8, issue 1, pp. 1-16.

Wamba, S.F., Gunasekaran, A., Akter, S., Ren, S.J., Dubey, R. and Childe, S.J. (2017). Big data analytics and firm performance: Effects of dynamic capabilities. Journal of Business Research, vol. 70, 356-365.

Wang, Y., Kung, L. and Byrd, T.A. (2018). Big data analytics: Understanding its capabilities and potential benefits for healthcare organizations. Technological Forecasting and Social Change, vol. 126, pp. 3-13.

Zhu, M. (2014). Housing Markets, Financial Stability and the Economy. $\quad$ [revised $2020 \quad 07 \quad 23]$, https://www.imf.org/en/News/Articles/2015/09/28/04/53/ sp060514. 
Beyza Ali. University of Information Science and Technology "St. Paul the Apostle", Faculty of Communication Networks and Security; Master. E-mail: beyzaali34@gmail.com. Mobile: +38970910466. Adress: ul. Dame Gruev no:138, 6000, Ohrid, Macedonia. Fields of scientific interest: machine learning and data mining.

Nikolai Siniak. Professor of the department of management and economics, Private Institute of Management and Business, 1/3 Slavinskogo Street, 220086, Minsk, Belarus Phone: +375173698049, Mobile: +375295674132, Email: siniakn@mail.ru, Skype name: nikki20093Web site: https://imb.by/ 